\title{
Communication
}

\section{A simplified method for reconstituting active E. coli DNA polymerase III}

\author{
Shi-Qiang Lin ${ }^{1,3}$, Li-Jun $\mathrm{Bi}^{1 凶}$, Xian-En Zhang $^{2 \bowtie}$ \\ ${ }^{1}$ National Laboratory of Biomacromolecules, Institute of Biophysics, Chinese Academy of Sciences, Beijing 100101, China \\ ${ }^{2}$ State Key Laboratory of Virology, Wuhan Institute of Virology, Chinese Academy of Sciences, Wuhan 430071, Hubei province, \\ China \\ ${ }^{3}$ Graduate School, Chinese Academy of Sciences, Beijing 100039, China \\ $\triangle$ Correspondence: blj@sun5.ibp.ac.cn (LJ. Bi), x.zhang@wh.iov.cn (XE. Zhang) \\ Received March 7, 2011 Accepted March 20, 2011
}

\begin{abstract}
Genome duplication in $E$. coli is carried out by DNA polymerase III, an enzyme complex consisting of ten subunits. Investigations of the biochemical and structural properties of DNA polymerase III require the expression and purification of subunits including $\alpha, \varepsilon$, $\theta, Y, \delta ', \delta$, and $\beta$ separately followed by in vitro reconstitution of the pol III core and clamp loader. Here we propose a new method for expressing and purifying DNA polymerase III components by utilizing a protein coexpression strategy. Our results show that the subunits of the pol III core and those of the clamp loader can be coexpressed and purified based on inherent interactions between the subunits. The resulting pol III core, clamp loader and sliding clamp can be reconstituted effectively to perform DNA polymerization. Our strategy considerably simplifies the expression and purification of DNA polymerase III and provides a feasible and convenient method for exploring other multi-subunit systems.
\end{abstract}

KEYWORDS E. coli, DNA polymerase III, coexpression, purification

\section{INTRODUCTION}

Genetic information stored in genomic DNA must be duplicated from generation to generation and that is exactly where DNA replicase finds its place in the cell. Much of what is known about DNA replicase comes from investigation of replicases from prokaryotic and eukaryotic model organisms (Johnson and O'Donnell, 2005). Replicative DNA polymerases of several organisms have been successfully reconstructed in vitro (Bruck and O'Donnell, 2000; Bruck et al., 2002; Bullard et al., 2002; Bruck et al., 2005).

In E. coli, replicative DNA polymerase III (referred to hereafter as DNA pol III) consists of three components, namely the pol III core, a sliding clamp and a clamp loader (Bruck and O'Donnell, 2000). The pol III core is made up of an a subunit encoded by $d n a E$, an $\varepsilon$ subunit encoded by $d n a Q$ and a $\theta$ subunit encoded by holE. The $\beta$ clamp encoded by $d n a N$ is a ring-shaped dimer that encircles and slides along the DNA. The association of the pol III core with the $\beta$ clamp makes it possible for pol III to replicate with speed and processivity. The clamp loader consists of five subunits in vivo, namely the $\mathrm{Y}($ dnaX), $\delta$ (holA), $\delta$ ' (holB), $\mathrm{X}(\mathrm{holC})$, and $\psi$ (holD) subunits; however, in vitro, the $\gamma, \delta$ and $\delta$ ' subunits are sufficient for clamp loading (Naktinis et al., 1995; Onrust et al., 1995a, 1995b; Stukenberg and O'Donnell, 1995; Xiao et al., 1995).

Biochemical and structural studies on E. coli DNA pol III require expression and purification of all of the subunits, one at a time. The subunits obtained are then reconstituted in vitro to form the pol III core and the clamp loader. Here, we propose an alternative method for expressing and purifying pol III components based on the inherent interactions of their member subunits. A protein coexpression strategy (Tolia and Joshua-Tor, 2006) was applied in this study in an attempt to simplify the expression and purification process. Results showed that the purified pol III core, clamp loader and sliding clamp are jointly capable of performing DNA polymerization, showing that our method can successfully reconstitute $E$. coli DNA polymerase III. This method may be a useful tool for investigating DNA pol III in other organisms and for reconstituting other complex biochemical systems. 


\section{RESULTS}

\section{Construction of pol III core and clamp loader expression systems}

We utilized Duet vectors (Merck) to coexpress the pol III core and clamp loader in this study. Both the pol III core and clamp loader consist of three genes; thus two coexpression vectors, pACYCDuet-1 and pETDuet-1, were used to construct plasmids for protein expression of each complex. To construct pol III core expression vectors, $d n a E$ and $d n a Q$ were cloned into the MCS-1 of pACYCDuet-1 and pETDuet-1, respectively. Appropriate selection of restriction sites ensured that HisTags were preserved for use in Ni-NTA affinity chromatography. holE was cloned into the MCS-2 of pETDuet-1, and lacked a HisTag or STag. As a result, purification of the $\theta$ subunit (holE) depends on its binding to the a $(d n a E)$ or $\varepsilon$ (dnaQ) subunit. Likewise, $d n a X$ and holA were cloned into the MCS-1 of pACYCDuet-1 and pETDuet-1, respectively. holB was cloned into the MCS-2 of pETDuet-1, and lacked a HisTag or STag. Similarly, purification of the $\delta$ ' subunit relies on its association with the $y$ or $\delta$ subunit.

\section{Expression and purification of the pol III core and clamp loader}

A small-scale expression test showed that the subunits of the pol III core or the clamp loader can be coexpressed in BL21 (DE3) in a soluble form (Fig. 1), and that the apparent

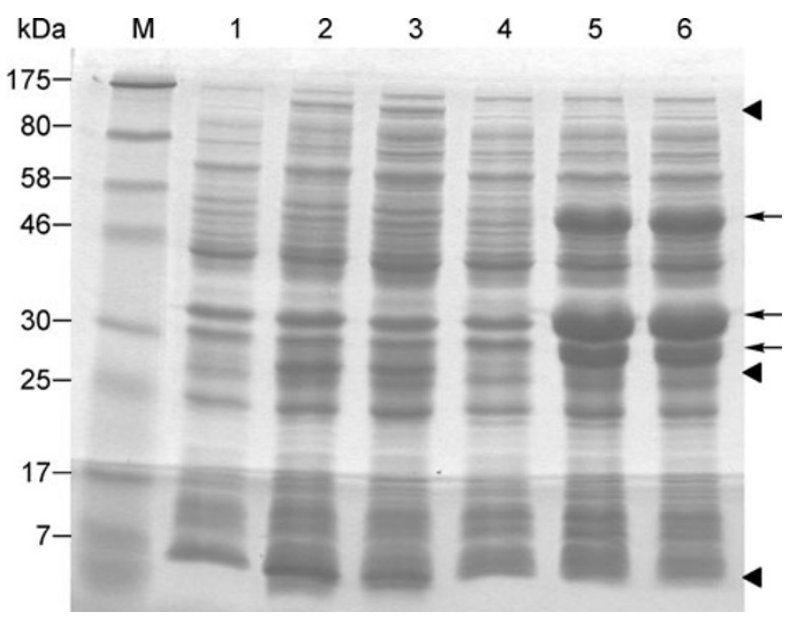

Figure 1. Bacterial expression of E. coli DNA pol III core (lanes 1-3) and clamp loader (lanes 4-6). In both groups of lanes, the first is the whole cell lysate of the uninduced sample (lanes 1 and 4), the second is the whole cell lysate of the IPTGinduced sample (lanes 2 and 5), and the third is the soluble fraction of the induced sample (lanes 3 and 6 ). The triangles on the right indicate the positions of the $\alpha, \varepsilon$ and $\theta$ sub-units, and the arrows show the positions of the $\gamma, \delta$ and $\delta$ ' subunits. The gel consisted of three layers of different gel concentrations $(5 \%, 12 \%$, and $15 \%)$ from top to bottom. molecular weight of each subunit was consistent with its corresponding theoretical molecular weight. If these soluble subunits could associate in vivo in a manner strong enough to withstand Ni-NTA purification, then the expression, purification and reconstitution of the pol III core and clamp loader would be greatly simplified. To test this, we performed Ni-NTA purification of the pol III core followed by the clamp loader. Results showed that the pol III core and clamp loader are both capable of being co-purified (Fig. 2), suggesting that interactions among the $\alpha, \varepsilon$ and $\theta$ subunits and interactions among the $\gamma, \delta$ and $\delta$ ' subunits are strong.

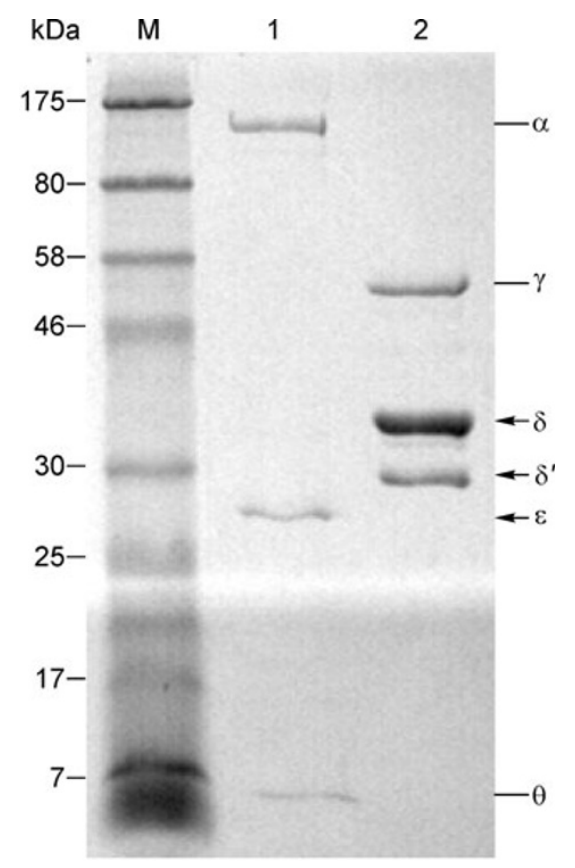

Figure 2. SDS-PAGE of the purified E. coli DNA pol III core and clamp loader. Lane M: protein marker; lane 1: pol III core; lane 2: clamp loader. The gel consisted of three layers of different gel concentrations $(5 \%, 12 \%$, and $15 \%)$ from top to bottom.

During the purification process, it is important to adjust the $\mathrm{NaCl}$ and imidazole concentrations to optimize removal of unwanted proteins. Some of these unwanted proteins bind nonspecifically to the Ni-NTA resin, while others associate with target proteins via protein-protein interactions. In our experiments non-targeted proteins were largely removed since interactions of target proteins with the resin and interactions among subunits were much stronger than nonspecific interactions.

Stoichiometry of the subunits is another important factor, which cannot be controlled during the expression and purification process. We tried to further purify the complex using MonoQ (GE Healthcare), but unfortunately the subunits underwent degradation during purification. Considerable 
effort is required to overcome or reduce degradation during subsequent purification processes.

\section{DNA polymerization activity assays for the purified pol III core and clamp loader}

To test the DNA polymerization activity of the obtained pol III core and clamp loader, a gap filling experiment was conducted. The DNA substrate used was a double-stranded M13mp18 with a gap of about $2 \mathrm{~kb}$. The $\beta$ clamp, clamp loader and pol III core were added in turn to the reaction system to fill the gap in the substrate DNA. Differences in migration rates between gapped and nicked DNA during electrophoresis make it possible to monitor gap filling activity (Fig. 3). As the activity of the purified pol III core and clamp loader were quite strong, $5 \mathrm{nmol} / \mathrm{L}$ of pol III core and clamp loader was sufficient for the gap filling activity assay. Figure 3 shows that most of the gapped DNA was filled to the nicked form after $2 \mathrm{~h}$ of incubation at $37^{\circ} \mathrm{C}$, confirming that the pol III core and clamp loader obtained in this study had DNA polymerization activity.

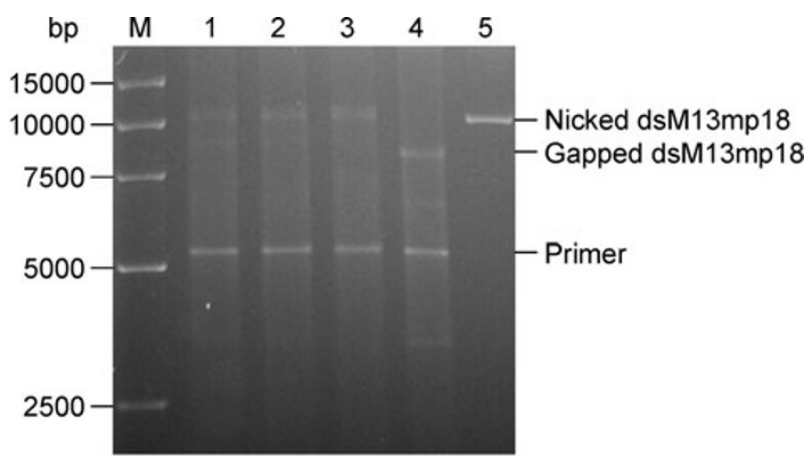

Figure 3. Filling in of the gapped dsM13mp18 by E. coli DNA pol III components. M: DL15000; lanes 1, 2 and 3: DNA substrate after filling with $5 \mathrm{nmol} / \mathrm{L}$ of the pol III core, $5 \mathrm{nmol} / \mathrm{L}$ of the clamp loader and $10 \mathrm{nmol} / \mathrm{L}$ of $\beta$ for $30 \mathrm{~min}, 1 \mathrm{~h}$ and $2 \mathrm{~h}$, respectively; lane 4: DNA substrate; lane 5: nicked dsM13mp18. Primer: the larger fragment of dsM13mp18.

\section{DISCUSSION}

In this report, we have presented a coexpression and purification strategy for obtaining E. coli DNA pol III core and clamp loader and a gap filling experiment that verifies its catalytic activity. The simplicity and effectiveness of our strategy provides a useful tool for studying DNA pol III from other bacteria.

In each of the complexes of three subunits, one subunit $(\theta$ in pol III core and $\delta$ ' in clamp loader) bears no affinity tag. The subunits associate strongly in vivo during expression to form a complex that is capable of withstanding the ensuing harsh purification process. The copy numbers of pACYCDuet-1 (10-12 per cell) and pETDuet-1 (about 40 per cell) are known to be different (Merck). In addition, the mRNA stability of each gene and the liability of each subunit to degradation might also be different. Thus, it is quite unlikely that the actual production of each subunit will be the same. In our experiment, the HisTags of the two subunits are designed for Ni-NTA purification while the protein without a HisTag helps to balance stoichiometry during Ni-NTA purification.

The strategy is also flexible in that for coexpression and purification of either of the triple subunits, one subunit can be removed during plasmid construction without affecting purification as two of the three subunits have affinity tags. The subunit can then be replaced by its counterpart from other bacteria during the gap filling experiment to test the interchangeability of the subunits from two DNA pol III systems. This system provides an alternative strategy when in vivo complementation experiments for the DNA pol III subunit do not work (Wechsler and Gross, 1971; Horiuchi et al., 1978; Strauss et al., 2004).

\section{MATERIALS AND METHODS}

\section{Construction of expression vectors}

dnaE (GenelD:6061238) was amplified from E. coli K-12 with an upstream primer (5'-CGCGGATCCGATGTCTGAACCACGT-3' containing a BamHI site) and a downstream primer (5'-CGAGCTCTTAGTCAAACTCCAGTT-3' containing a Sacl site). The PCR product was digested with BamHI and Sacl and ligated to the MCS-1 of pACYCDuet-1 (Merck) to produce pACYCDuet-a. dnaQ (GenelD:6061081) was amplified from E. coli K-12 with an upstream primer (5'-CGGAATTCGATGAGCACTGCAATT-3' containing an EcoRI site) and a downstream primer (5'-GGGAAGCTTTTATGCTCGCCAGA-3' containing a HindIII site). The PCR product was digested with ECORI and HindIII and ligated to the MCS-1 of pETDuet-1 (Merck) to produce PETDuet- $\varepsilon$. holE (GenelD:6060582) was amplified from E. coli $\mathrm{K}-12$ with an upstream primer (5'GGAATTCCATATGCTGAAGAATCTGG-3' containing an Ndel site) and a downstream primer (5'-CGGCTCGAGTTATTTAAGTTTGGGC3 ' containing an $\mathrm{Xhol}$ site). The PCR product was digested with $\mathrm{Ndel}$ and $X$ hol, and ligated to the MCS-2 of PETDuet- $\varepsilon$ to produce PETDuet- $\varepsilon \theta$. After the above three genes were confirmed by DNA sequencing, pACYCDuet- $\alpha$ and PETDuet- $\varepsilon \theta$ were co-transformed into $E$. coli BL21(DE3) competent cells to produce BL21(DE3)/Duet $\alpha \varepsilon \theta$ for expressing the pol III core.

dnaX (GenelD:6059726) was amplified from pQE30-dnaX (constructed previously by $\mathrm{Li}$ et al. (2008)) with an upstream primer (5'CGGAATTCGATGAGTTATCAGGT-3' containing an EcoRI site) and a downstream primer (5'-GGGAAGCTTTCATTCCTTTTTTG-3' con-

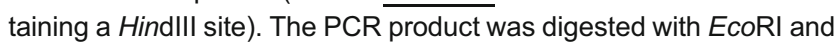
HindIII, and then ligated to the MCS-1 of PACYCDuet-1 to produce pACYCDuet-y. The holA (GenelD:6061561) was amplified from pQE30-holA (constructed previously by Li et al. (2008)) with an upstream primer (5'-CGGAATTCGATGATTCGGTTGTA-3' containing an EcoRI site) and a downstream primer (5'-GGGAAGCTTTCAACCGTCGATAA-3' containing a HindIII site). The PCR product was digested with EcoRI and HindIII, and ligated into pETDuet-1 to produce pETDuet- $\delta$. holB (GenelD:6058796) was amplified from pQE30-holB (constructed previously by Li et al. (2008)) with an upstream primer (5'-GGAATTCCATATGAGATGGTATCCAT-3' with 
an Ndel site) and a downstream primer (5'-CGGCTCGAGTCAAAGATGAGGAA-3' with an Xhol site). The PCR product was digested with Ndel and Xhol, and then ligated to the MCS-2 of pETDuet- $\delta$ to produce $p E T D u e t-\delta \delta$ '. After the above three genes were confirmed by DNA sequencing, pACYCDuet- $\gamma$ and pETDuet- $\delta \delta$ ' were co-trans-

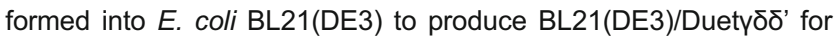
expressing the clamp loader.

M15/pQE30-dnaN (GenelD: 6058510, constructed previously (Li et al., 2008)) was used to express the $\beta$ clamp.

\section{Expression and purification of E. coli DNA pol III components}

For expression of the pol III core, BL21(DE3)/Duet $\alpha \varepsilon \theta$ was streaked onto a solid LB plate containing $100 \mu \mathrm{g} / \mathrm{mL}$ ampicillin and $34 \mu \mathrm{g} / \mathrm{mL}$ chloramphenicol and incubated overnight at $37^{\circ} \mathrm{C}$. Cells from a single clone were then grown in LB in the presence of $100 \mu \mathrm{g} / \mathrm{mL}$ ampicillin and $34 \mu \mathrm{g} / \mathrm{mL}$ chloramphenicol at $37^{\circ} \mathrm{C}$. As the $\mathrm{OD}_{600}$ reached about $0.8,2 \mathrm{~mL}$ of the bacterial culture was inoculated in $200 \mathrm{~mL}$ LB in the presence of $100 \mu \mathrm{g} / \mathrm{mL}$ ampicillin and $34 \mu \mathrm{g} / \mathrm{mL}$ chloramphenicol at $37^{\circ} \mathrm{C}$ and cultured until the $\mathrm{OD}_{600}$ reached about 0.8 . IPTG was added to a final concentration of $0.4 \mu \mathrm{mol} / \mathrm{L}$ and induction continued for $3 \mathrm{~h}$. Cells were collected by centrifuging at $4000 \mathrm{~g}$ for $10 \mathrm{~min}$ at $4^{\circ} \mathrm{C}$, and were then re-suspended in binding buffer $(20 \mathrm{mmol} / \mathrm{L}$ Tris-Cl, $\mathrm{pH} 7.9 ; 500 \mathrm{mmol} / \mathrm{L} \mathrm{NaCl} ; 5 \mathrm{mmol} / \mathrm{L}$ imidazole), lysed by ultrasonification and centrifuged with a SS-34 rotor at 16,000 rotation/min for $30 \mathrm{~min}$ at $4^{\circ} \mathrm{C}$. The supernatant was loaded onto a Ni-NTA column (GE Healthcare) equilibrated with binding buffer. 3-5 volumes of binding buffer was applied to equilibrate the column and $3-5$ volumes of wash buffer $(20 \mathrm{mmol} / \mathrm{L}$ Tris- $\mathrm{Cl}, \mathrm{pH} 7.9 ; 500 \mathrm{mmol} / \mathrm{L} \mathrm{NaCl}$; $90 \mathrm{mmol} / \mathrm{L}$ imidazole) was used to wash out unwanted proteins. Finally, the target protein was eluted with 3-5 volumes of elution buffer $(20 \mathrm{mmol} / \mathrm{L}$ Tris-Cl, pH 7.9; $500 \mathrm{mmol} / \mathrm{L} \mathrm{NaCl} ; 250 \mathrm{mmol} / \mathrm{L}$ imidazole). The eluted proteins were concentrated via ultra-filtration and stored in storage buffer $(50 \mathrm{mmol} / \mathrm{L}$ Tris-Cl, $\mathrm{pH} 7.5 ; 100 \mathrm{mmol} / \mathrm{L}$ $\mathrm{NaCl} ; 5 \mathrm{mmol} / \mathrm{L}$ DTT; $0.025 \mathrm{mmol} / \mathrm{L}$ EDTA; $20 \%$ glycerol $(v / \mathrm{v}))$ at $-20^{\circ} \mathrm{C}$. Protein concentration was determined using Thermo Scientific Pierce Coomassie Plus Assay Reagent (Thermo) according to the manufacturer's instructions.

Procedures for the expression and purification of the clamp loader were the same as those for the pol III core, while $\beta$ clamp was expressed and purified as described by Li et al. (2008).

\section{Preparation of the gapped dsM13mp18 DNA substrate}

The gapped dsM13mp18 DNA substrate was prepared according to the method of Kunkel (Kunkel, 1985) with a minor adjustment. The dsM13mp18 was digested with EcoRI and BsrGI, and the resultant larger fragment was recycled. Competent annealing was conducted with the larger fragment (in excess) and the ssM13mp18 in SSC buffer, denatured for $10 \mathrm{~min}$ at $94^{\circ} \mathrm{C}$ and slowly cooled to room temperature. The annealed mixture was then utilized as the substrate for DNA pol III polymerization reactions. Nicked dsM13mp18 was prepared as a marker by digesting dsM13mp18 with $\mathrm{Nb}$.BtsI (NEB \#R0707).

\section{DNA pol III gap filling experiment}

The gap filling reaction was conducted according to the method of Bruck and O'Donnell (Bruck and O'Donnell, 2000) with some adjustments. The volume of the reaction mixture was $20 \mu \mathrm{L}$ and contained $20 \mathrm{mmol} / \mathrm{L}$ Tris-Cl (pH 7.5), $0.1 \mathrm{mmol} / \mathrm{L}$ EDTA, $\mathrm{pH} 8.0$, $5 \mathrm{mmol} / \mathrm{L}$ DTT, $40 \mu \mathrm{g} / \mathrm{mL}$ BSA, $2 \mathrm{mmol} / \mathrm{L}$ ATP, $8 \mathrm{mmol} / \mathrm{L} \mathrm{MgCl}_{2}, 4 \%$ glycerol $(v / v)$ and $60 \mu \mathrm{mol} / \mathrm{L}$ dNTP, $80 \mathrm{ng}$ DNA substrate, $5 \mathrm{nmol} / \mathrm{L} \mathrm{pol}$ III core (calculated at a stoichiometry of $\alpha: \varepsilon: \theta=1: 1: 1), 5 \mathrm{nmol} / \mathrm{L}$ clamp loader (calculated at a stoichiometry of $\mathrm{Y}: \delta: \delta^{\prime}=1: 1: 1$ ), and $10 \mathrm{nmol} / \mathrm{L}$ $\beta$. The mixture was preincubated for $5 \mathrm{~min}$ at room temperature and then incubated at $37^{\circ} \mathrm{C}$ for different lengths of time. The reaction was terminated with $1 \mu \mathrm{L} 10 \%$ SDS $(w / v)$, prior to the addition of $0.5 \mu \mathrm{L}$ $20 \mathrm{mg} / \mathrm{mL}$ Proteinase K (NEB) to digest the proteins. The mixture was then subjected to electrophoresis in a $1 \%$ agarose gel $(w / v)$ in TAE buffer at a constant $18 \mathrm{~V}$ for $20 \mathrm{~h}$. The gel was soaked in $0.5 \mu \mathrm{g} / \mathrm{mL}$ ethidium bromide (Promega) for $10 \mathrm{~min}$ and photographed with Alphalmager 2200.

\section{ACKNOWLEDGEMENTS}

This work was supported by the National Basic Research Program of China (Grant Nos. 2009CB522605 and 2011CB910302), the Key Project Specialized for Infectious Diseases from the Ministry of Health of China (No. 2008ZX10003-005), the Chinese Academy of Sciences (Grant No. KSCX2-YW-R-164) and the National Natural Science Foundation of China (Grant No. 30970590).

\section{REFERENCES}

Bruck, I., Georgescu, R.E., and O'Donnell, M. (2005). Conserved interactions in the Staphylococcus aureus DNA PolC chromosome replication machine. J Biol Chem 280, 18152-18162.

Bruck, I., and O'Donnell, M. (2000). The DNA replication machine of a gram-positive organism. J Biol Chem 275, 28971-28983.

Bruck, I., Yuzhakov, A., Yurieva, O., Jeruzalmi, D., Skangalis, M., Kuriyan, J., and O'Donnell, M. (2002). Analysis of a multicomponent thermostable DNA polymerase III replicase from an extreme thermophile. J Biol Chem 277, 17334-17348.

Bullard, J.M., Williams, J.C., Acker, W.K., Jacobi, C., Janjic, N., and McHenry, C.S. (2002). DNA polymerase III holoenzyme from Thermus thermophilus identification, expression, purification of components, and use to reconstitute a processive replicase. J Biol Chem 277, 13401-13408.

Horiuchi, T., Maki, H., and Sekiguchi, M. (1978). A new conditional lethal mutator (dnaQ49) in Escherichia coli K12. Mol Gen Genet 163, 277-283.

Johnson, A., and O'Donnell, M. (2005). Cellular DNA replicases: components and dynamics at the replication fork. Annu Rev Biochem 74, 283-315.

Kunkel, T.A. (1985). The mutational specificity of DNA polymerasebeta during in vitro DNA synthesis. Production of frameshift, base substitution, and deletion mutations. J Biol Chem 260, 5787-5796.

Li, F., Liu, Q., Chen, Y.Y., Yu, Z.N., Zhang, Z.P., Zhou, Y.F., Deng, J.Y., Bi, L.J., and Zhang, X.E. (2008). Escherichia coli mismatch repair protein MutL interacts with the clamp loader subunits of DNA polymerase III. Mutat Res 637, 101-110.

Naktinis, V., Onrust, R., Fang, L., and O'Donnell, M. (1995). Assembly of a chromosomal replication machine: two DNA polymerases, a clamp loader, and sliding clamps in one holoenzyme particle. II. Intermediate complex between the clamp loader and its clamp. J Biol Chem 270, 13358-13365.

Onrust, R., Finkelstein, J., Naktinis, V., Turner, J., Fang, L., and 
O'Donnell, M. (1995a). Assembly of a chromosomal replication machine: two DNA polymerases, a clamp loader, and sliding clamps in one holoenzyme particle. I. Organization of the clamp loader. J Biol Chem 270, 13348-13357.

Onrust, R., Finkelstein, J., Turner, J., Naktinis, V., and O'Donnell, M. (1995b). Assembly of a chromosomal replication machine: two DNA polymerases, a clamp loader, and sliding clamps in one holoenzyme particle. III. Interface between two polymerases and the clamp loader. J Biol Chem 270, 13366-13377.

Strauss, B., Kelly, K., Dincman, T., Ekiert, D., Biesieda, T., and Song, R. (2004). Cell death in Escherichia coli dnaE(Ts) mutants incubated at a nonpermissive temperature is prevented by mutation in the cydA gene. J Bacteriol 186, 2147-2155.

Stukenberg, P.T., and O'Donnell, M. (1995). Assembly of a chromosomal replication machine: two DNA polymerases, a clamp loader, and sliding clamps in one holoenzyme particle. V. Four different polymerase-clamp complexes on DNA. J Biol Chem 270, 13384-13391.

Tolia, N.H., and Joshua-Tor, L. (2006). Strategies for protein coexpression in Escherichia coli. Nat Methods 3, 55-64.

Wechsler, J.A., and Gross, J.D. (1971). Escherichia coli mutants temperature-sensitive for DNA synthesis. Mol Gen Genet 113, 273-284.

Xiao, H., Naktinis, V., and O'Donnell, M. (1995). Assembly of a chromosomal replication machine: two DNA polymerases, a clamp loader, and sliding clamps in one holoenzyme particle. IV. ATPbinding site mutants identify the clamp loader. J Biol Chem 270, 13378-13383. 